\title{
Atomic Species Recognition on Oxide Surfaces Using Low Temperature
}

\section{Scanning Probe Microscopy}

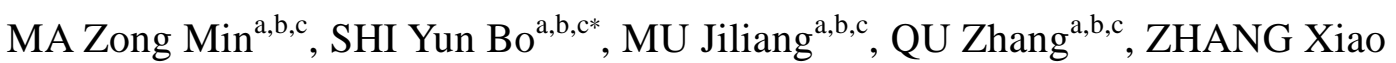 \\ Ming $^{\mathrm{a}, \mathrm{b}, \mathrm{c}}, \mathrm{QIN} \mathrm{Li}^{\mathrm{a}, \mathrm{b}, \mathrm{c}}$, and LIU Jun ${ }^{\mathrm{a}, \mathrm{b}, \mathrm{c*}}$
}

\author{
${ }^{a}$ National Key Laboratory for Electronic Measurement Technology, North University of China, \\ Taiyuan, 030051, China \\ ${ }^{b}$ Key Laboratory of Instrumentation Science \& Dynamic Measurement, North University of China, \\ Ministry of Education, Taiyuan, 030051, China \\ ${ }^{c}$ School of Instrument and Electronics, North University of China, Taiyuan, 030051, China
}

In scanning probe microscopy (SPM), the chemical properties and sharpness of the tips of the cantilever greatly influence the scanning of a sample surface. Variation in the chemical properties of the sharp tip apex can induce transformation of the SPM images. In this research, we explore the relationship between the tip and the structure of a sample surface using dynamic atomic force microscopy (AFM) on a $\mathrm{Cu}(110)$-O surface under ultra-high vacuum $(\mathrm{UHV})$ at low temperature $(78 \mathrm{~K})$. We observed two different $\mathrm{c}(6 \times 2)$ phase types in which super- $\mathrm{Cu}$ atoms show as a bright spot when the tip apex is of $\mathrm{O}$ atoms and $\mathrm{O}$ atoms show as a bright spot when the tip apex is of $\mathrm{Cu}$ atoms. We also found that the electronic state of the tip has a serious effect on the resolution and stability of the sample surface, and provide an explanation for these phenomena. This technique can be used to identify atom species on sample surfaces, and represents an important development in the SPM technique.

Keywords: Scanning probe microscope; Oxide Surface; Atomic Recognition

PACS: 07.79.Cz, 07.79.Fc, 07.79.Lh 


\section{Introduction}

Scanning probe microscopy (SPM) technologies, such as scanning tunneling microscopy (STM) and dynamic atomic force microscopy (AFM), are basic methods currently used in nanotechnology, and are expected to be used in future bottom-up processes, such as the surface characterization, control, and recognition of atoms or molecules at nano atomic scales.[1,2] STM, which is based on the electric tunneling current effect between the conductive tip and the sample surface, can electrically observe individual atoms/molecules, characterize or analyze the electronic nature around surface atoms/molecules, and even manipulate individual atoms/molecules on conductor/semiconductor surfaces.[3] However, STM cannot be applied to insulator surface imaging due to the large band gap between the tip and the sample surface. In contrast, AFM directly measures the forces induced by the tip apex and sample surface, and is a unique mechanically-based atomic tool that can deal with conductor, semiconductor, and insulator surfaces.[1, 4] Both AFM and non-contact AFM (NC-AFM) have rapidly developed into powerful surface tools at the atomic/molecular scale because of their high resolution, force and elastic deformation detection capabilities, and measurement of the distribution of potential and charge.[5-8]

Tip termination is also a key technique used in SPM measurements.[9-11] Sharp and specific tip apexes of cantilevers in AFM and STM can be used to discriminate between chemically different atoms on a surface structure, and to examine the different geometric and electronic structures of surfaces with real-space atomic resolution.[12, 13]

In the past, STM/NC-AFM imaging and force spectroscopy have been frequently used to investigate metal oxides, and especially $\mathrm{Cu}(110)-\mathrm{O}$, which is of great importance in many 
fields,[16-19] including microelectronics and catalysis.[14,15] The $\mathrm{Cu}$ (110)-O surface develops different phases depending on its degree of exposure to oxygen. At low oxygen exposures (less than $\left.100 \mathrm{~L}, 1 \mathrm{~L}=1.33 \times 10^{4} \mathrm{~Pa} \bullet \mathrm{s}\right)$, a $\mathrm{p}(2 \times 1)$ phase forms,[20] and as the exposure increases the $\mathrm{p}(2 \times 1)$ structure endures[21-23] until at 2/3 oxygen coverage, at an exposure in the order of $10^{3} \mathrm{~L}$, a transient $\mathrm{c}(6 \times 2)$ structure occurs .[16,23, 24] At an exposure of $10^{4}-10^{5} \mathrm{~L}$, the surface is predominantly covered with the $c(6 \times 2)$ structure. ${ }^{[24]}$ The $\mathrm{p}(2 \times 1)$ phase, which is generally accepted as an "add row" (AR), has been studied extensively, both theoretically and experimentally. The $\mathrm{c}(6 \times 2)$ phase, which has a double AR structure, exhibits additional copper atoms in every second row, known as "super" copper atoms, bound between two oxygen atoms.[20, 25] As a result, oxygen atoms bonded to copper atoms are raised slightly out of plane and buckled in toward the super-Cu atoms. These are called "high" or "buckled" oxygen atoms. The arrangement of $\mathrm{Cu}$ and $\mathrm{O}$ atoms on the $\mathrm{Cu}(110)-\mathrm{O}$ surface significantly influences its properties.[22-28]

Some researchers have performed experiments using STM and AFM under ultra-high vacuum (UHV) conditions to clarify the relationship between the tip apex and the observable atoms on the $\mathrm{Cu}(110)-\mathrm{O}$ surface in different phases. They found that the state of the tip apex (i.e., the sharpness of the tip and atomic species of the tip apex) plays a crucial role in STM and AFM atomic-scale imaging.[24] Theoretical and experimental NC-AFM results under UHV at low temperature have shown that when the tip apex is an $\mathrm{O}$ atom, the protrusions on the $\mathrm{p}(2 \times 1)$ and $\mathrm{c}(6 \times 2)$ surfaces are $\mathrm{Cu}$ atoms, and when the tip apex is a $\mathrm{Cu}$ atom, the protrusions on the $\mathrm{p}(2 \times 1)$ and $\mathrm{c}(6 \times 2)$ surfaces are $\mathrm{O}$ atoms. Surprisingly, in STM and AFM experiments at room temperature, no protrusions of $\mathrm{O}$ atoms can be observed using any 
tip apex. This is because the interaction and dipole moment between the tip apexes and atoms differ.[23, 29, 30] Also, the sharpness of the tip apex determines the resolution on the $\mathrm{Cu}(110)-\mathrm{O}$ surface, so when the tip apex is sharp enough, it is possible to achieve sub-atomic resolution of the sample surface.[31, 32]

In this study, we successfully used NC-AFM at $78 \mathrm{~K}$ under UHV conditions to observe the $\mathrm{p}(2 \times 1)$ and $\mathrm{c}(6 \times 2)$ phases. and mixture structures produced depending on the amount of oxygen exposure. We also confirmed that the species of the tip apex determines the surface structure, and that the sharpness of the tip apex can induce various atomic images on the $\mathrm{Cu}$ (110)-O surface. We provide an explanation for these experimental results, and note that this research has important implications for AFM imaging and can also shed light on chemical recognition with respect to the SPM technique.

\section{Experimental details}

We conducted all experiments using a home-built NC-AFM equipped with a sputter-ion gun operating under a ultrahigh vacuum (less than $5 \times 10^{-11}$ Torr) and high-pressure oxygen at $75 \mathrm{~K}$, for which the thermal drift was less than $0.05 \AA / \mathrm{min}$.

The $\mathrm{Cu}(110)$ substrate had a maximum disorientation of $0.4^{\circ}$ and a purity of $99.999 \%$ (metal crystals \& oxides). We cleaned the $\mathrm{Cu}$ (110) surface by repeated $\mathrm{Ar}^{+}$ion sputtering $\left(1.4 \mathrm{keV}\right.$ ) for $20 \mathrm{~min}$, then annealed it at $500{ }^{\circ} \mathrm{C}$ for $40 \mathrm{~min}$ for at least 15 cycles. This procedure removed contaminants and residual charges from the surface and yielded atomically flat terraces, which we then imaged with AFM. We then exposed the surface to $2000 \mathrm{~L}$ of oxygen at $300{ }^{\circ} \mathrm{C}$. We generated the mixture phases of $\mathrm{c}(6 \times 2)$ and $\mathrm{p}(2 \times 1)$ on the 
$\mathrm{Cu}(110)$ surface, after which we transferred the sample into the main chamber. The cleaning process and oxygen exposure are illustrated in Figs. 1(a) and 1(b), respectively.

We used the frequency-modulation technique ${ }^{[33]}$ to detect the tip-sample interaction, and used commercial silicon cantilevers (n-doped, 0.01-0.025 $\Omega \mathrm{cm}$, Nano world, Switzerland), with a resonance frequency, spring constant, and quality factor of $160 \mathrm{kHz}, 40 \mathrm{~N} / \mathrm{m}$, and 150,000 , respectively, as the sensor, which was set to maintain a constant oscillation amplitude at $5.6 \mathrm{~nm}$. We detected the deflection signal of the cantilever using an optical beam deflection system, and measured the frequency shift of the oscillating cantilever using phase-locked-loop-based commercial electronics (easyPLL plus detector and controller, Nano surf, Switzerland) fed into two loops. In one loop, we used a phase-locked loop (PLL) circuit and automatic gain (AGC) as feedback to maintain constant amplitude and frequency of the cantilever (Nanonis System, SPECS Zurich GmbH, Switzerland). In the other loop, we used the frequency shift $(\Delta f)$ of the cantilever to maintain a constant distance between the tip and sample (SPECS, Zurich GmbH).

We cleaned the commercially available $\mathrm{Si}$ cantilever by $\mathrm{Ar}^{+}$ion bombardment at an energy level of $1.2 \mathrm{keV}$ in situ for $20 \mathrm{~min}$; the radius of the cantilever was less than $10 \mathrm{~nm}$. Both the cantilever and the sample were electrically grounded throughout the experiment.

Initially, the sharp silicon tip was used to scan the $\mathrm{CuO}$ surface with large scanning area $(100 \mathrm{~nm} \times 100 \mathrm{~nm})$. Then, we confirmed that there are a few $\mathrm{Cu}-\mathrm{O}$ clusters distributed on the $\mathrm{CuO}$ surface. After that, we moved the tip over a specific cluster and intentionally crashed into it. After we confirmed the tip was still stable, a smaller area was scanned with the stable soft contact tip and two different types of images were obtained with respect to variation of 
the tip apex in the end. We can assume that a $\mathrm{Cu}-\mathrm{O}$ cluster was terminated the $\mathrm{Si}$ cantilever.

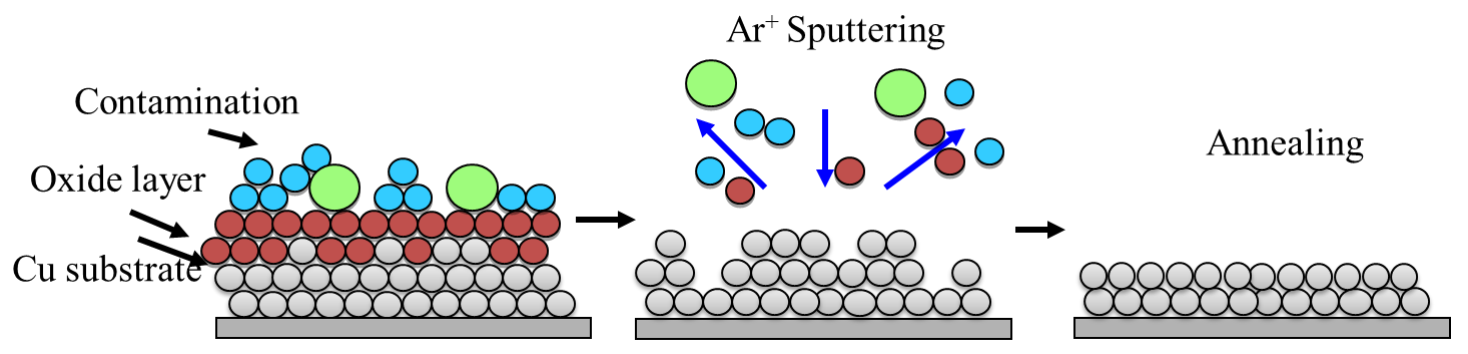

(a)

Cu: Face-centered cubic (fcc).

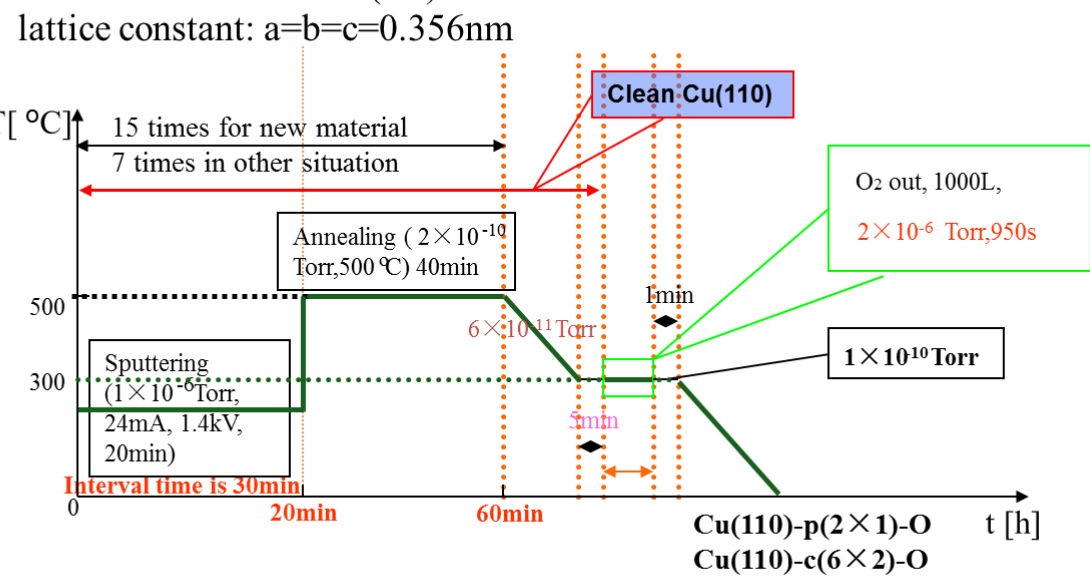

(b)

Fig. 1. (a) Schematic diagram of the cleaning process of the $\mathrm{Cu}$ (110) surface and (b) the mixture structures of $\mathrm{p}(2 \times 1)$ and $\mathrm{c}(6 \times 2)$ for $\mathrm{Cu}(110)-\mathrm{O}(\mathrm{b})$.

\section{Results and discussion}

The $\mathrm{p}(2 \times 1)$ phase, shown in Fig. 2 (a), has an alternating/missing row in the (110) direction, where along the (001) rows we confirmed the presence of alternating $\mathrm{Cu}$ and $\mathrm{O}$ atoms. The $\mathrm{p}(2 \times$ 1) phase was formed with an oxygen coverage of $1 / 2$ monolayer $(\mathrm{ML})$. In the $\mathrm{c}(6 \times 2)$ phase, oxygen-induced reconstruction occurred at a higher oxygen exposure and shows a double 
row/missing row structure, in which the $\mathrm{Cu}$ and $\mathrm{O}$ atoms alternate along the (001) direction, and a missing row is also confirmed in the (110) direction. In every second missing row, additional super- $\mathrm{Cu}$ atoms are bonded between two oxygen atoms, which lie higher than the other atoms, as shown in Fig. 2(b). We can recognize the super-Cu atoms by their different and distinguishable ordering from the $\mathrm{O}$ atoms on the $\mathrm{c}(6 \times 2)$ surface. We can directly distinguish between $\mathrm{p}(2 \times 1)$ and $\mathrm{c}(6 \times 2)$ structures by their super- $\mathrm{Cu}$ and $\mathrm{O}$ atoms. The transition between $\mathrm{p}(2 \times 1)$ and $\mathrm{c}(6$ $\times 2$ ) has been confirmed by Sun et al. and Shohei Kishimoto et al.[33,34]

At oxygen exposures of $2000 \mathrm{~L}$ on the $\mathrm{Cu}(110)$ surface, $\mathrm{p}(2 \times 1)$ and $\mathrm{c}(6 \times 2)$ phases of oxidized $\mathrm{Cu}(110)$ are formed. Fig. 3 shows atomic-resolution topographic images of (a) a large area, (b) an enlarged image from (a), and (c) a cross-section. The oxidized $\mathrm{Cu}$ (110) shown in Fig. 3(a) has a step height of approximately $2.43 \AA$, which we confirmed by the cross-section labeled in Fig. 3(c). We clearly observed $\mathrm{Cu}$ atoms with a spacing of $5.10 \AA$, which corresponds to the distance between the super-Cu atoms in the $\mathrm{c}(6 \times 2)$ phase (Fig. 3(b)). 

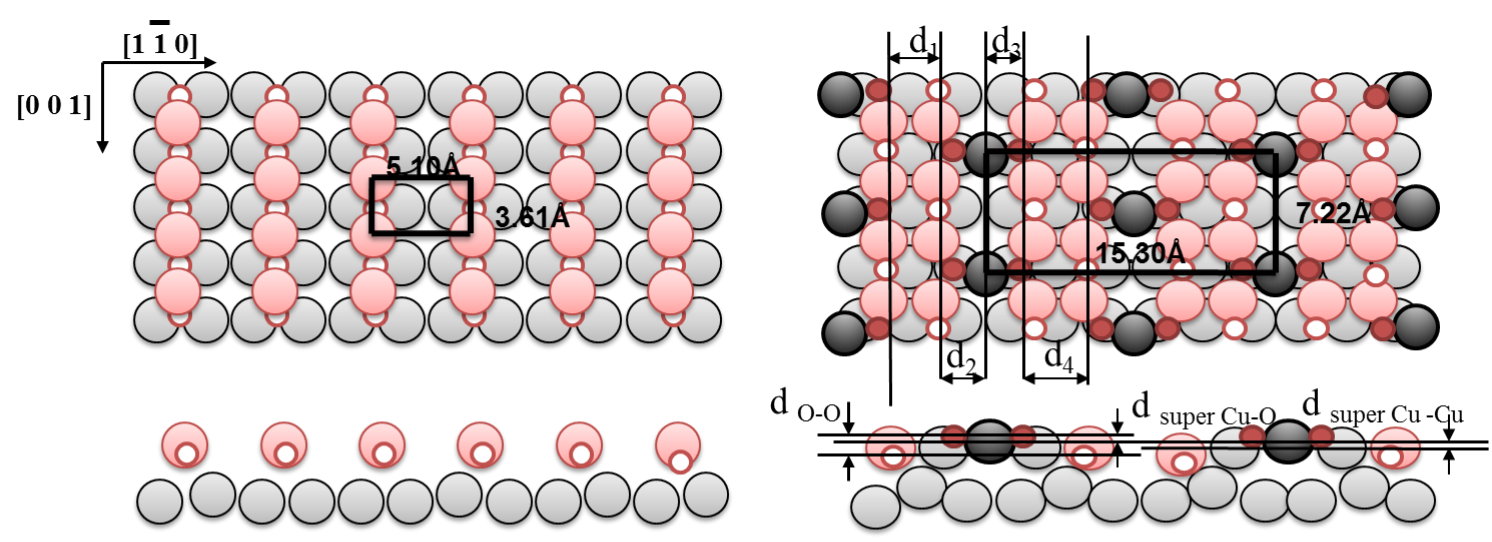

$\bigcirc$ Super $\mathrm{Cu} \bigcirc$ Added $\mathrm{Cu} \bigcirc$ Surface $\mathrm{Cu} \odot$ High $\mathrm{O} \bigcirc$ Low $\mathrm{O}$

(a)

(b)

\begin{tabular}{ccccccc}
\hline \hline $\mathrm{d}_{1}$ & $\mathrm{~d}_{2}$ & $\mathrm{~d}_{3}$ & $\mathrm{~d}_{4}$ & $\mathrm{~d}_{\mathrm{O}-\mathrm{O}}$ & $\mathrm{d}_{\text {super } \mathrm{Cu}-\mathrm{O}}$ & $\mathrm{d}_{\text {super } \mathrm{Cu}-\mathrm{Cu}}$ \\
\hline $3.13 \AA$ & $2.26 \AA$ & $1.82 \AA$ & $3.44 \AA$ & $0.48 \AA$ & $0.02 \AA$ & $0.29 \AA$ \\
\hline \hline
\end{tabular}

(c)

Fig. 2. (a) Ball model of the p $(2 \times 1)$ phase (top and side views), where light red, gray and light gray balls depict low $\mathrm{O}$, added $\mathrm{Cu}$, and bulk $\mathrm{Cu}$ atoms, respectively.

(b) Ball model of the $\mathrm{c}(6 \times 2)$ phase (top and side views), where the additional dark gray and red balls depict the super-Cu and high-O atoms, respectively.
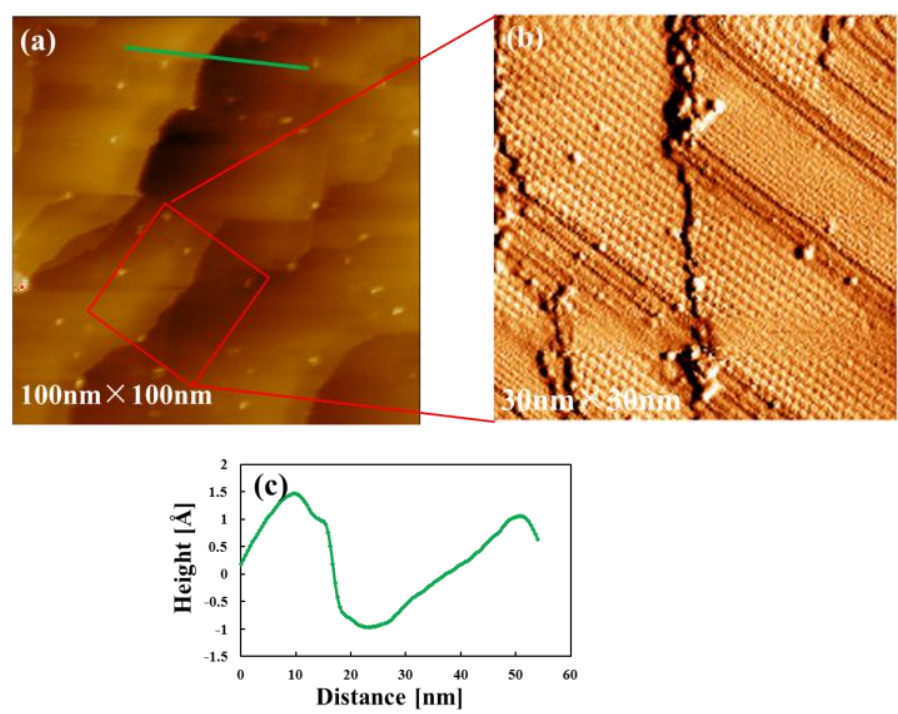
Fig. 3. Topography and line profiles of steps for oxidized $\mathrm{Cu}$ (110) with 2000-L exposure to oxygen. The scanning area is $100 \mathrm{~nm} \times 100 \mathrm{~nm}$, as shown in (a) and (c). The zoom image of (b) in (a) shows the atomic resolution details of the (110) terrace on $\mathrm{Cu}(110)-\mathrm{O}$ surface.

Fig. 4(a) shows the tip formation of types I and II, and two scanning images of the same area of the $c(6 \times 2)$ phase are shown in Figs. $4(\mathrm{~b})$ and $4(\mathrm{c})$, respectively. We confirmed that when a pure silicon tip is used to soft crash several times into a $\mathrm{Cu}-\mathrm{O}$ cluster on the mixture surfaces of the $\mathrm{p}(2 \times 1)$ and $\mathrm{c}(6 \times 2)$ phases by controlling the variation frequency $\Delta f$ until contact (soft contact), the $\mathrm{Cu}-\mathrm{O}$ cluster is pushed onto the tip apex, and two types of tip are formed-type I and type II. When scanning the sample surface using a type-I tip, we observed a bright spot at the expected positions of the super- $\mathrm{Cu}$ atoms. As a result, we can see that the surface species of the tip apex is oxygen. Using the same method, when scanning the sample surface using a type-II tip, two close spots are imaged instead, located at around the same position as in type I. We attribute these spots to the two high-O atoms. As a result, the surface species of the tip apex is $\mathrm{Cu} .[16,35]$

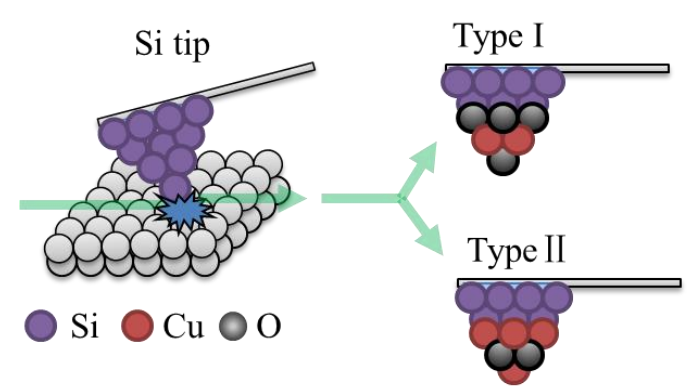

(a)

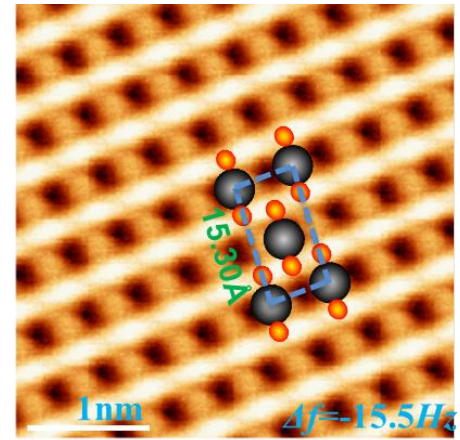

(b)

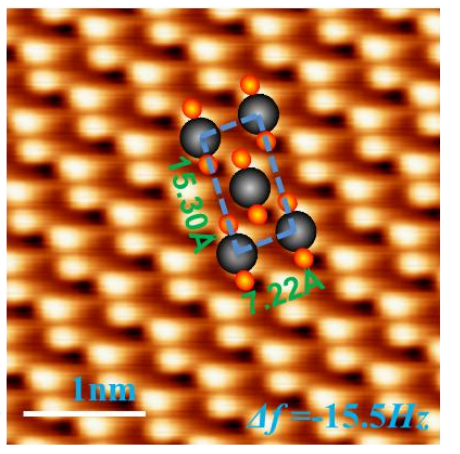

(c)

Fig. 4. (a) Schematic diagram of the formation for tip types I and II. (b) Scanning the same area 
over the $\mathrm{c}(6 \times 2)$ phase on oxidized $\mathrm{Cu}(110)$ surface with tip type I and (c) tip type II.

To further demonstrate the dependence of the tip apex species on image contrast, we decreased the tip-sample separation by decreasing the frequency shift from $-17.5 \mathrm{~Hz}$ to $-20.0 \mathrm{~Hz}$ using the type-II tip apex during scanning. Initially, the super oxygen showed bright spots, Fig. 5(a), and then the tip apex changed due to the interaction between it and the oxygen on the sample surface during the scan. As a result, the contrast in the sample surface in which super-Cu atoms were imaged changed. According to the previous results, we can say that the tip apex changed from type II ( $\mathrm{Cu}$ termination) to type $\mathrm{I}(\mathrm{O}$ termination) due to the interchange of $\mathrm{Cu}$ and $\mathrm{O}$ atoms between the tip apex and sample surface. The topographic cross-section decreased by approximately $0.46 \AA$ when this interchange occurred, Fig. 5(b), and increased by approximately $0.2 \AA$ when the species of the tip apex changed to oxygen atoms. Figs. 5(b) and 5(d) shows the dissipation information and cross-sections when the tip apex change occurred during the scan. Fig. 5(d) shows that a variation in the dissipation occurred at approximately $42 \mathrm{mV}$, but no obvious change occurred during the interchange of the tip apex. These results are highly reproducible and validate the species of the tip apex in the image contrast on the $\mathrm{Cu}(110)-\mathrm{O}$ surface. That is, the contrast of the $\mathrm{Cu}$ or oxygen atoms is indicated by bright spots when the tip apex terminates either with $\mathrm{O}$ or $\mathrm{Cu}$, when operated at low temperatures in experimental NC-AFM. 

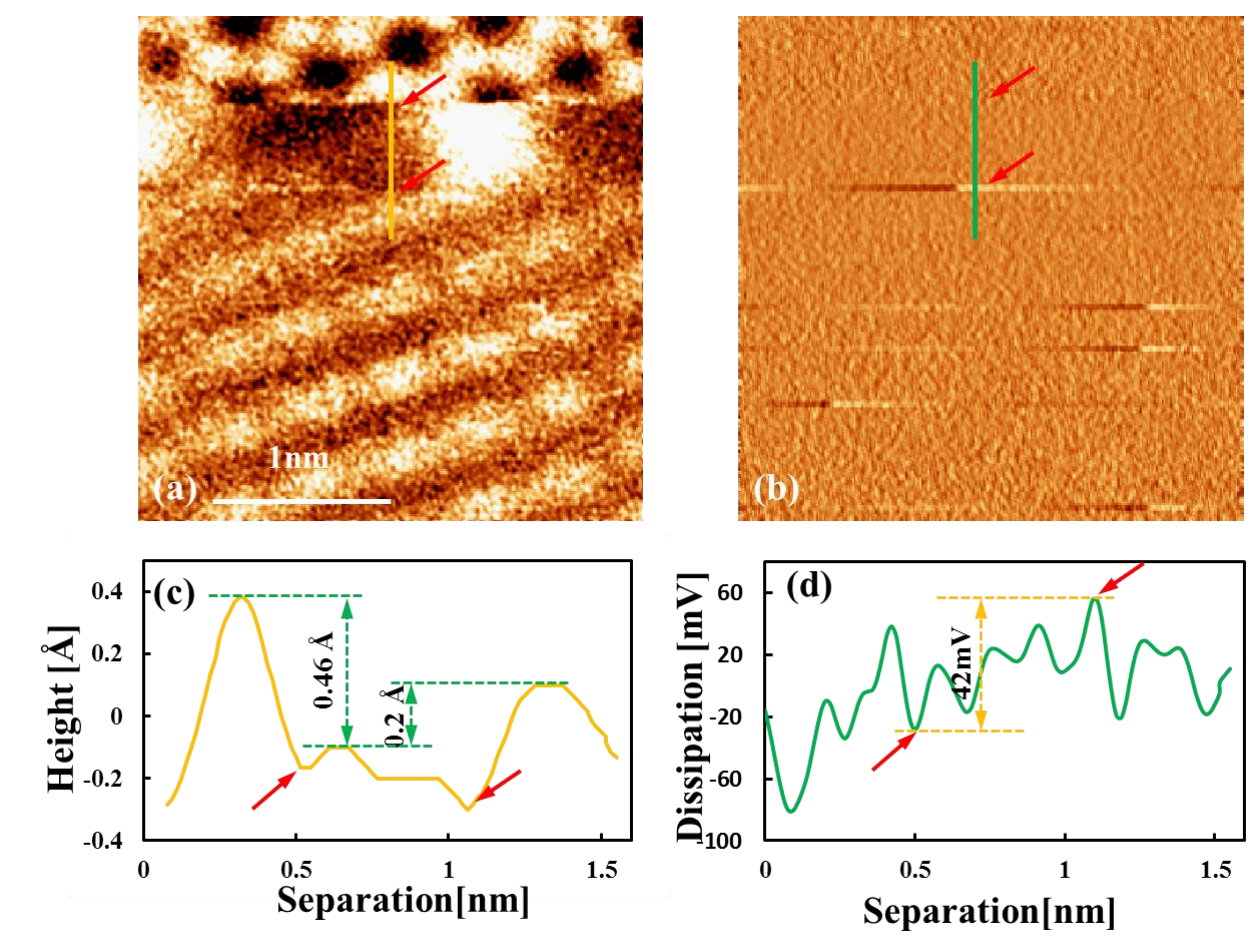

Fig. 5. Topography and dissipation during change of species of the tip apex on the oxidized $\mathrm{Cu}(110)$ surface (a), (b) and the cross-sections (c) and (d), respectively.

These findings represent information essential for determination of the species of $\mathrm{Cu}$ and $\mathrm{O}$ atoms and for the interpretation of the atomic structures in the $\mathrm{p}(2 \times 1)$ phase, before and during scanning of the mixture structure on the $\mathrm{Cu}(110)-\mathrm{O}$ surface. Figs. 6(a) and 6(b) show the topographies of the same mixture structure area for the $\mathrm{p}(2 \times 1)$ and $\mathrm{c}(6 \times 2)$ phases on the $\mathrm{Cu}-\mathrm{O}$ surface, with $\mathrm{O}$-terminated and $\mathrm{Cu}$-terminated tips, respectively. In Fig. 6(a), super-Cu atoms show as bright spots and $\mathrm{O}$ atoms show as dark spots on the $\mathrm{c}(6 \times 2)$ structure with the O-terminated tip, which is consistent with the model shown on the right side of Fig. 6(a). Hence, the bright/dark spots are also $\mathrm{Cu} / \mathrm{O}$ atoms in the $\mathrm{p}(2 \times 1)$ phase, respectively, because each tip 
only images one species. When scanning the same area with a Cu-terminated tip in Fig. 6(b), O atoms show as bright spots and super- $\mathrm{Cu}$ atoms show as dark spots on the $\mathrm{c}(6 \mathrm{x} 2)$ structure, which can be seen in the model on the right side of Fig. 6(b). Hence, the bright/dark spots are also $\mathrm{O} / \mathrm{Cu}$ atoms in the $\mathrm{p}(2 \times 1)$ phase.

To further validate these results, we took cross-section measurements of the super-Cu and high-O atoms, marked as bright green lines in Figs. 6(a) and 6(b), using WSxM5.0 software. In Fig. 6(c), when super-Cu shows a bright protrusion with an O-terminated tip, it is higher than the $\mathrm{O}$ atoms, at a height $d_{\text {super Cu-O }}$ of $0.002 \mathrm{~nm}$. The distance, $d_{3}$, between the super-Cu and high-O atoms is $0.160 \mathrm{~nm}$. In Fig. 6(d), when high-O shows a bright protrusion with a Cu-terminated tip, the $\mathrm{O}$ is higher than the super- $\mathrm{Cu}$ atoms, at a height $d_{\text {super } \mathrm{Cu}-\mathrm{Cu}}$ of $0.023 \mathrm{~nm}$. The distance between the super- $\mathrm{Cu}$ and high-O is $1.359 \mathrm{~nm}$. These results are consistent with the theoretical results, in which the value of $d_{\text {super } \mathrm{Cu}-0}$ is $0.002 \mathrm{~nm}, d_{3}$ is $0.182 \mathrm{~nm}, d_{\text {super } \mathrm{Cu}-\mathrm{Cu}}$ is $0.029 \mathrm{~nm}$, and $d_{\text {super } \mathrm{Cu}-\text { super }}$ $\mathrm{Cu}_{\mathrm{u}}$ is $1.530 \mathrm{~nm}$. This shows that we obtained atomic resolution on $\mathrm{p}(2 \times 1)$ and $\mathrm{c}(6 \mathrm{x} 2)$ mixture structures on a $\mathrm{Cu}(110)-\mathrm{O}$ surface with two types of tips, and each tip-definitely defines the image patterns with one atom species. This technique can be applied to the recognition of atom species in future nano fingerprint fields.

The chemical identification of the tip apex atom during the course of NC-AFM experiments was also investigated on $\mathrm{Cu}(110)-\mathrm{O}$ and $\mathrm{Cu}(100)-\mathrm{O}$ surface experimentally and theoretically [12, 41]. It has been demonstrated that image contrast inversion was contributed to tip terminated by $\mathrm{Cu}$ or $\mathrm{O}$ atoms; specifically, to the chemical forces between the tip apex and the sample surface. 
When the tip is O-terminated, the force between the Oxygen and the Super $\mathrm{Cu}$ is attractive, and repulsive between the Oxygen tip and Oxygen on the surface. Therefore, $\mathrm{Cu}$ atoms shows protrusion and Oxygen looks dark spot on the $\mathrm{Cu}(110)-\mathrm{O}$ surface. In contrast, when the tip is $\mathrm{Cu}$-terminated, the force between the $\mathrm{Cu}$ tip and Oxygen atom is attractive, and repulsive between the $\mathrm{Cu}$-tip and $\mathrm{Cu}$ on the surface. Hence, $\mathrm{Cu}$ atoms shows dark spots and Oxygen looks protrusion on the surface.
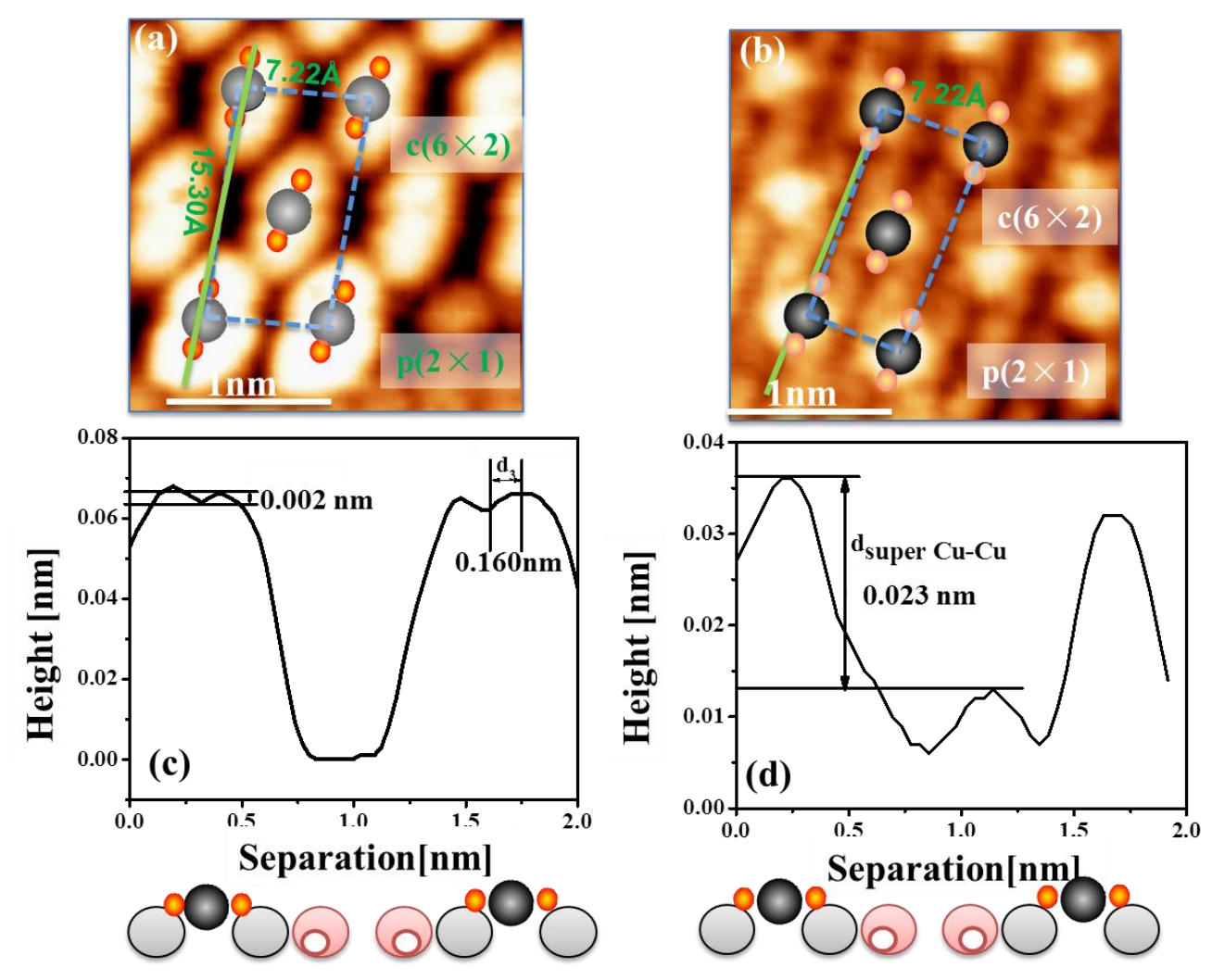

Fig. 6. Topographic images of the $\mathrm{c}(6 \times 2)$ and $\mathrm{p}(2 \times 1)$ mixture on an oxidized $\mathrm{Cu}(110)$ surface, performed using (a) Cu-terminated and (b) O-terminated tips. (c) and (d) are the cross-sections of the same scanning areas, respectively. A corresponding schematic of the $\mathrm{c}(6 \times 2)$ 
surface is provided to highlight the imaged atoms.
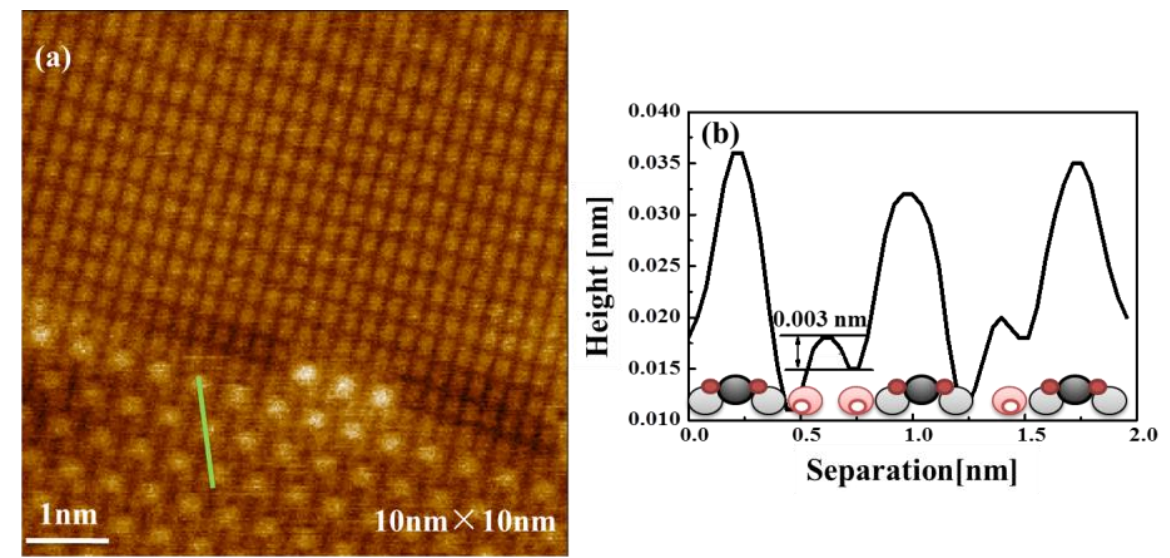

Fig. 7. Topography (a) and cross-section (b) marked in blue lines in (a) of $\mathrm{Cu}(110)-\mathrm{O}$ surface using O-terminated tip.

We also found that the condition of the tip apex has significant influence on the resolution of the scanning image after the tip species is defined, with respect to its sharpness, charge, and dipole. Figs. 7(a) and 7(b) show the topography and cross-section, respectively, marked in green lines in Fig. 7(a) of the p ( $2 \times 1)$ and $\mathrm{c}(6 \times 2)$ mixture structures on the $\mathrm{Cu}(110)-\mathrm{O}$ surface with one O-terminated tip apex. From this image, we see that the super atoms are relatively smaller than those in Fig. 7(b). We seem to be observing atoms in the sub-layer, and a protrusion of the second layer with a height of $0.003 \mathrm{~nm}$ can be seen. This contrast can be explained as follows: a contact potential difference $V_{\mathrm{CPD}}$ arises due to the difference in the Fermi levels between the tip and the sample surface, and the dipole information was coupled with the topography. Further, a tunneling current was generated because coupling of $V_{\mathrm{CPD}}$ and the electrical density was inevitable during scanning when $V_{\mathrm{CPD}}$ was not zero. ${ }^{[36]}$ Finally, the tip apex is relatively sharper, and only super- $\mathrm{Cu}$ atoms with higher electrical density can be observed at the atomic scale. As a 
result, the super-Cu atom in Fig. 6 seems smaller, and we detected false sub-layer information instead. In order to solve these problems, the following steps should be taken: (1) Use a sharp tip of diameter less than $10 \mathrm{~nm}$ to detect more sensitively the short-range force between the tip and the sample surface; (2) Apply a bias voltage $V_{\text {bias }}$ with the opposite polarity and same magnitude as $V_{\mathrm{CPD}}$ to eliminate its influence. Consequently, KPFM or STM experiments can be performed simultaneously to completely separate the potential or electrical density information from the topography.[37-39]

\section{Conclusions}

In summary, we examined the relationship between species of the tip apex and the image type when operating at low temperatures under UHV with NC-AFM. Taking oxidized Cu (110) as an example, we observed two different types of image for its $\mathrm{p}(2 \times 1)$ and $\mathrm{c}(6 \times 2)$ phases when changing the tip apex species. Namely, when the tip apex was O-terminated, super-Cu atoms showed as bright spots, and when the tip apex was $\mathrm{Cu}$-terminated, high-O atoms showed as bright spots. Hence, we succeeded in controlling the species of the tip apex and the scanning image patterns in a dynamic SPM technique. Further, we explain that the condition of the tip apex, including its sharpness, charge, and dipole, has significant influence on the experimental resolution. We also provide a theoretical explanation. This technique is very useful for the chemical recognition of atoms and sheds light on bottom-up manufacturing at the atomic scale. 


\section{Acknowledgments}

The authors are appreciated the support from the National Science Foundation of China

(NSFC) under Grant No 61274103, 91336110, 51411140037 and 61503346, and support by

Natural Science Foundation of Shanxi (SXNSF) under Grant No 2014021023-2. We also thank

Prof. Li Yanjun from Osaka University for fruitful discussion.

\section{References}

1. S. Morita, R. Wiesendanger, E. Meyer: Noncontact Atomic Force Microscopy. Springer, Berlin, 2002.

2. Mohn, F.; Gross, L, Moll, N.; Meyer, G: Bond-Order Discrimination by Atomic Force Microscopy. Nat. Nanotechnol. 7 (2012) 227 - 231.

3.Saw-Wai Hla: STM Single Atom/Molecule Manipulation and Its Application to Nanoscience and Technology. J. Vac. Sci. Tech.B. 23(2005) $1351-1360$.

4. F. J. Giessibl: Advances in Atomic Force Microscopy. Rev. Mod. Phys. 75 (2003) 949 -983.

5. Sugawara Y, Ohta M, Ueyama H and Morita S: Defect Motion on an $\operatorname{InP}(1$ 10) Surface Observed with Noncontact Atomic Force Microscopy. Science. 270 (1995)1646 - 1648.

6. U. Kaiser, A. Schwarz, R. Wiesendanger: Magnetic exchange force microscopy with atomic resolution. Nature: 446(2007) 522-525.

7. Nonnenmacher. M, O'Boyle M. P. and Wickramasinghe H. K.: Kelvin probe force microscope. Appl. Phys. Lett. 58(1991) 2921-2924.

8. S. Hembacher, F. J. Giessibl, and J. Mannhart: Local Spectroscopy and Atomic Imaging of Tunneling Current, Forces, and Dissipation on Graphite. Phys.Rev.Lett. 94(2005) 056101(1-4).

9. Y. L. Wang, H.-J. Gao, H. M. Guo: Tip size effect on the appearance of a STM image for complex surfaces: Theory versus experiment for Si(111)-7x7. Phys. Rev. B. 70(2004) 073312(1-4).

10. Y. Sugimoto et al., Chemical identification of individual surface atoms by atomic force microscopy. Nature. 446(2007) 64-67.

11. Y. Sugimoto, M. Abe, S. Hirayama, N. Oyabu, Ó. Custance, S. Morita, Atom inlays performed at room temperature using atomic force microscopy. Nat. Mater. 4(2005) 156-159.

12. Mehmet Z. Baykara, Milica Todorovi'c, Harry MÖnig, Todd C. Schwendemann,1 Ö zhan Ünverdi, Lucia Rodrigo, Eric I. Altman, Rub'en P'erez, and Udo D. Schwarz. Atom-specific forces and defect identification on surface-oxidized $\mathrm{Cu}(100)$ with combined 3D-AFM and STM measurements. Phys. Rev. B. 87 (2013)155414(1-9).

13. J. Bamidele, S.H. Lee, Y. Kinoshita, R. Turansky', Y. Naitoh, Y.J. Li, Y. Sugawara, I. S`tich \& L. Kantorovich. Vertical atomic manipulation with dynamic atomic-force microscopy without tip change via a multi-step mechanism. Nat. Comm. 5(2014) 4476.

14. Mehmet Z. Baykara, Omur. Dagdeviren, Yodd C. Schwendemann, Harry. Monig, Eric I. Altman, and Udo D. Schwarz. Probing three-dimensional surface force fields with atomic resolution: Measurement 
strategies, limitations, and artifact reduction. Beilstein J. Nanotechnology. 3(2012) 637-650.

15. Louis-Rose, I., Me'thivier, C. \& Pradier, C.-M. Oxidation of NH3 on polycrystalline copper and $\mathrm{Cu}(110)$ : a combined FT-IRAS and kinetics investigation. Catal. Today. 85(2003) 267-278.

16. J. Bamidele, Y. Kinoshita, R. Turansk et.al. Chemical tip fingerprinting in scanning probe microscopy of an oxidized $\mathrm{Cu}(110)$ surface. Phys.Rev.B. 86(2012)155422(1-8).

17. F. Mohn, L. Gross, N. Moll, et.al. Imaging the charge distribution within a single molecule. Nat Nanotechnology. 7(2012) 227-231.

18. W. Melitz, J. Shen, A. C. Kummel, et.al. Kelvin probe force microscopy and its application. Surf. Sci. 66(2011) 1-27.

19. Mehmet Z. Baykara, M. Todorović, H. Mönig, Todd C. Schwendemann, Ö. Ünverdi, L. Rodrigo, Eric I. Altman, R. Pérez, and Udo D. Schwarz. Atom-specific forces and defect identification on surface-oxidized $\mathrm{Cu}(100)$ with combined 3D-AFM and STM measurements. Phys. Rev. B. 87 (2013) 155414(1-9).

20. M.Sheik-Bahae, D. J. Hagan, and E. W. Van Stryland. Dispersion and band-gap scaling of the electronic Kerr effect in solids associated with two-photon absorption. Phys. Rev. Lett. 65 (1990) 96-99.

21. A. Gumbsch, G. Barcaro, M. G. Ramsey, S. Surnev, A. Fortunelli,2, and F. P. Netzer. Kondo effect of cobalt adatoms on nanostructured $\mathrm{Cu}-\mathrm{O}$ surfaces: Scanning tunneling spectroscopy experiments and first-principles calculations. Phys. Rev. B. 81(2010) 165420 (1-7).

22. A. Gumbsch, G. Barcaro, M. G. Ramsey, Svetlozar. Surnev, A. Fortunelli, F. P. Netzer. Kondo versus magnetic coupling of cobalt dimers in a $\mathrm{Cu}-\mathrm{O}(2 \times 1)$ reconstruction. J. Phys.: Condens. Matter. 22(2010)222202-222209.

23. Y.Hu, K. Maschek, L. D. Sun, M. Hohage, \& P. Zeppenfeld. Para-Sexiphenyl thin film growth on $\mathrm{Cu}(110)$ and $\mathrm{Cu}(110)-(2 \times 1) \mathrm{O}$ surfaces. Surf. Sci. 600(2006) 762-769.

24. M. Oehzelt, S. Berkebile, G. Koller, J. Ivanco, S.Surnev, M. G. Ramsey. Alpha-Sexithiophene on $\mathrm{Cu}(110)$ and $\mathrm{Cu}(110)-(2 \mathrm{x}$ 1)O: An STM and NEXAFS study. Surf. Sci. 603 (2009) 412-418.

25. W. Liu, W. Wong, K. C. Mitchell, K. A. R. Structural details for the Cu (110)-c (6× 2)-O surface determined by tensor LEED. Surf. Sci. 339(1995) 151-158.

26. S. Kishimoto, M. Kageshima, Y. Naitoh, Y. J. Li, Y. Sugawara. Study of oxidized Cu(1 100$)$ surface using noncontact atomic force microscopy. Surf. Sci. 602(2008) 2175-2182.

27. M. Wagner, S. Surnev, M. G. Ramsey, G. Barcaro, L. Sementa, F. R. Negreiros, A. Fortunelli, Z. Dohnalek, and F. P. Netzer. Structure and Bonding of Tungsten Oxide Clusters on Nanostructured Cu-O Surfaces. J. Phys. Chem. C, 115 (2011) 23480-23487.

28. N. Tsukahara, K. I. Noto, M. Ohara, S. Shiraki, N. Takagi, Y. Takata, J. Miyawaki, M. Taguchi, A. Chainani, S. Shin, and M. Kawai. Adsorption-Induced Switching of Magnetic Anisotropy in a Single Iron(II) Phthalocyanine Molecule on an Oxidized Cu(110) Surface. Phys. Rev. Lett, 102 (2009) 167203 (1-4).

29. S. P. Jarvis, H. Yamada, S. I. Yamamoto, H. Tokumoto, J. B. Pethica. Direct mechanical measurement of interatomic potentials. Nature, 384 (1996) 247-249.

30. X. Duan, O.Warschkow, A. Soon, B. Delley, C. Stampfl. Density functional study of oxygen on $\mathrm{Cu}(100)$ and $\mathrm{Cu}(110)$ surfaces. Phys. Rev. B, 81 (2010) 075430 (1-15).

31. Y. L. Wang, H.-J. Gao, H. M. Guo, H. W. Liu, I. G. Batyrev, W. E. MaMahon,and S. B. Zhang. Tip size effect on the appearance of a STM image for complex surfaces: Theory versus experiment for Si(111)-(7×7). Phys. Rev. B. 70 (2004) 073312 (1-4).

32. R. S. Becker, B. S. Swartzentruber, J. S. Vickers, T. Klitsner. Dimer-adatom-stacking-fault (DAS) and 
non-DAS (111) semiconductor surfaces: A comparison of $\mathrm{Ge}(111)-\mathrm{c}(2 \times 8)$ to $\mathrm{Si}(111)-(2 \times 2),-(5 \times 5)$, $-(7 \times 7)$, and $-(9 \times 9)$ with scanning tunneling microscopy. Phys. Rev. B. 39 (1989) 1633-1647.

33. T. R. Albrecht, P. Grutter, D. Horne, D. Rugar. Frequency modulation detection using high-Q cantilevers for enhanced force microscope sensitivity. J. Appl. Phys, 69(1991) 668-673.

34. L. D. Sun, M. Hohage, and P. Zeppenfeld. Oxygen-induced reconstructions of $\mathrm{Cu}(110)$ studied by reflectance difference spectroscopy. Phys. Rev. B, 69 (2004) 045407 (1-6).

35. L. Ruan, F. Besenbacher, I. Stensgaard, E. Laegsgaard. Atom resolved discrimination of chemically different elements on metal surfaces. Phys. Rev. Lett. 70 (1993) 4079-4082.

36. S.H.Ke, T. Uda, I. Stich, K. Terakura. First-principles simulation of atomic force microscopy image formation on a GaAs(110) surface: Effect of tip morphology. Phys. Rev. B. 63 (2001) 245323 (1-7).

37. J. Tobik, I. Stich, and K. Terakura. Effect of tip morphology on image formation in noncontact atomic force microscopy: InP(110). Phys. Rev. B, 63 (2001) 245324 (1-6).

38. T. Wutsher, A. J. Weymouth, F. J. Giessibl. Localization of the phantom force induced by the tunneling current. Phys. Rev. B, 85 (2012)195426 (1-7).

39. Z. M. Ma, J. L. Mu, J. Tang, H. Xue, H. Zhang, C.Y. Xue, J. Liu and Y. J. Li. Potential sensitivities in frequency modulation and heterodyne amplitude modulation Kelvin probe force microscopes. Nanoscale Research Letters. 8 (2013) 532 (1-6).

40. J. Bamidele, Y. Kinoshita, R. Turansk'y, S. H. Lee, Y. Naitoh, Y. J. Li, Y. Sugawara, I. ` Stich, and L. Kantorovich. Physical Review B. 90 (2014) 035410 (1-7). 

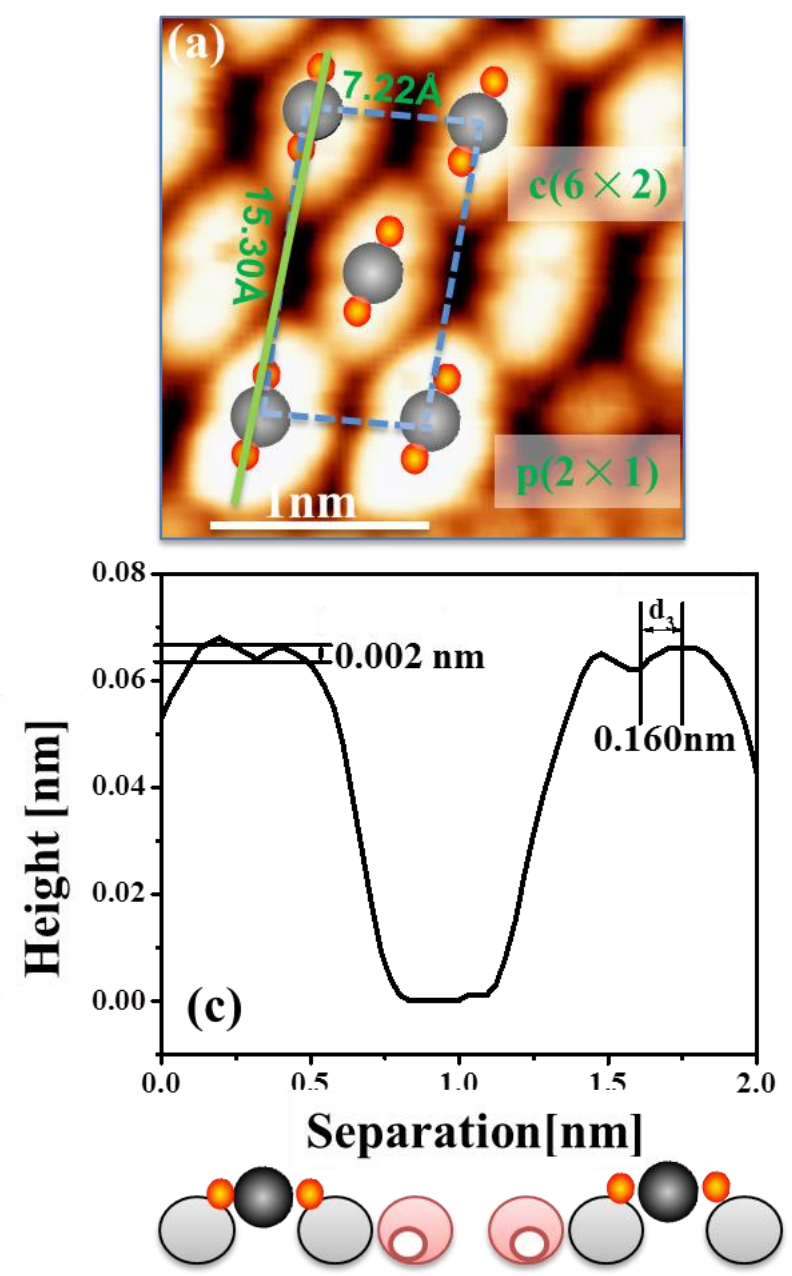

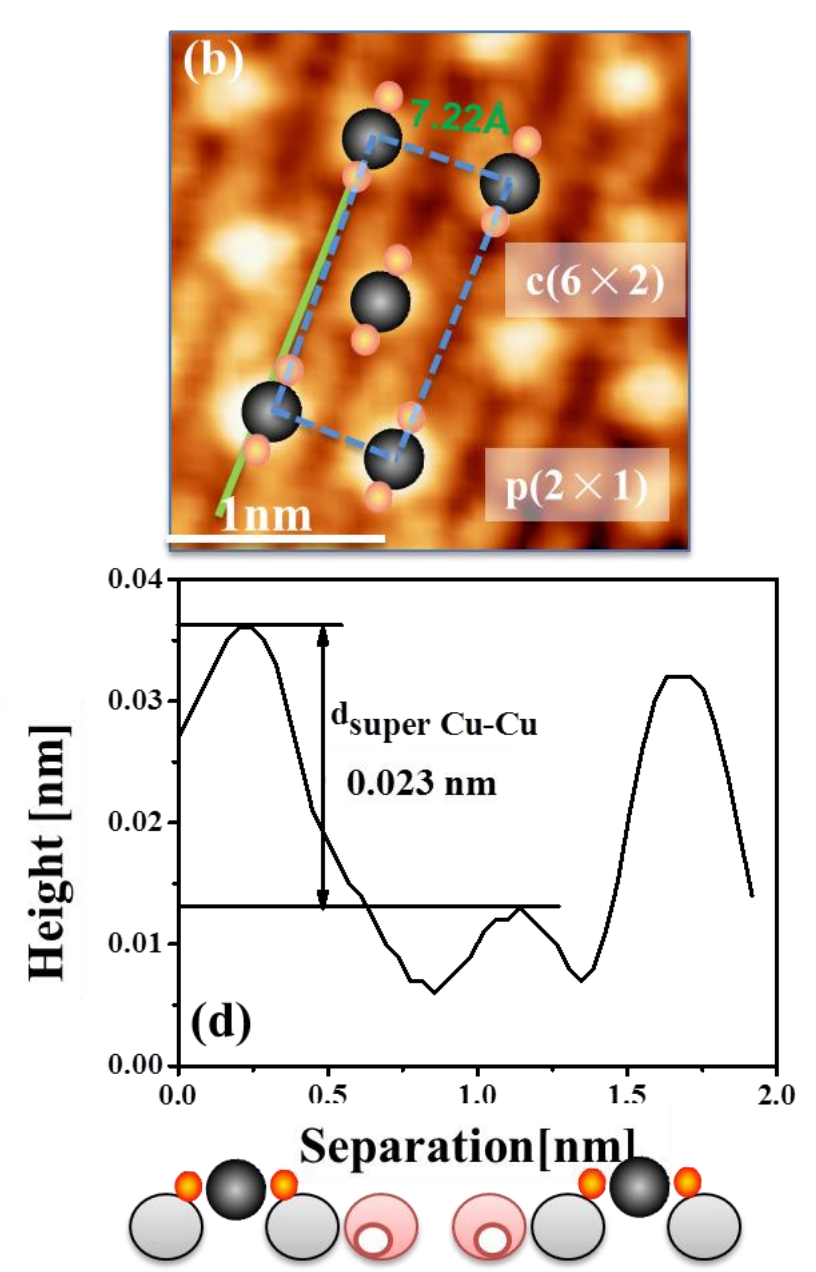

Fig. 6. Topographic images of the $\mathrm{c}(6 \times 2)$ and $\mathrm{p}(2 \times 1)$ mixture on an oxidized $\mathrm{Cu}(110)$ surface, performed using (a) Cu-terminated and (b) O-terminated tips. (c) and (d) are the cross-sections of the same scanning areas, respectively. A corresponding schematic of the $\mathrm{c}(6 \times 2)$ surface is provided to highlight the imaged atoms. 